\title{
Pathogenesis and Therapy of Pseudomonas aeruginosa Keratitis
}

\author{
J K G DART and D V SEAL
}

London

\begin{abstract}
Summary
Considerable progress has been made recently in understanding the pathogenesis of pseudomonas keratitis including its adhesion, invasion and the role of the glycocalyx. Adhesion to epithelial cells has been shown in vitro to depend on pili but their relationship to the glycocalyx biofilm has yet to be explored. The actions of its toxins and proteases have been established by studying the effects of deletion mutants. However, in animal models pseudomonads have been unable to cause an invasive infection in the presence of an intact corneal epithelium and have required associated trauma. Why early necrosis of the cornea can occur in an immunocompetent individual is still not clear but may reflect the delayed access of polymorphonuclear cells (PMNs) in an avascular tissue. Whether the corneal necrosis that later occurs is then due to the PMNs or pseudomonas toxins is not established. Topical fortified gentamicin therapy remains the treatment of choice for early infection. The use of medical and surgical adjunctive therapy is often needed to cope with the complications of advanced disease and has been reviewed.
\end{abstract}

Pseudomonas aeruginosa is well recognised as an ocular pathogen causing severe keratitis, corneoscleritis and endophthalmitis. Keratitis may result in corneal melting and perforation. However, Ps. aeruginosa is an opportunistic pathogen and certain factors are required for the establishment of keratitis such as trauma, the presence of pre-existing ocular disease including Herpes simplex infection, immunosuppression, an association with wearing of soft contact lenses or use of contaminated solutions and possibly genetic predisposition. Host factors are also important as polymorphonuclear cell function is primarily responsible for preventing invasion of tissue. Adults have not been reported to disseminate the infection outside the ocular tissues although this has occurred in premature infants.

Animal models have been pursued to identify initiating factors of pseudomonas keratitis. Adult rabbits, guinea pigs and mice are susceptible to develop experimental keratitis but only if corneal abrasion is performed or large numbers of bacteria are injected intra-stromally. ${ }^{1}$ The mouse model has been further used to identify genetic determinants in strains susceptible and resistant to corneal infection. ${ }^{2}$ Microscopic examination of mouse and rabbit cornea has shown necrosis of epithelial, keratocytes and endothelial cells and, in both animals and humans, degradation of collagen fibrils with extensive dissolution of the stroma.

\section{Specific Virulence Factors}

Both cell-associated and extra-cellular products of Ps. aeruginosa contribute to its virulence. ${ }^{3}$ Surface structures include pili and the polysaccharide capsule (or glycocalyx), both 
involved in initial attachment to host cells. Extracellular enzymes viz exotoxin $\mathrm{A}$ and $\mathrm{S}$ which inhibit protein synthesis of host cells, proteases, leukocidin and haemolysins degrade infected tissue and promote invasion.

\section{Bacterial Surface-Associated Factors:}

The attachment of Ps. aeruginosa to traumatised corneal epithelial cells, but not to intact epithelium, has been studied in a mouse model by Ramphal et $\mathrm{al}^{4}$ and in the rabbit by Stern et al. ${ }^{5}$ They showed by electron microscopy that pseudomonas adhered only to the injured areas and the exposed stroma. Stern et al showed that stromal invasion occurred within one hour, when bacteria were rarely seen on the cell surface or in the epithelial defect, and that many bacteria had migrated between the basal epithelium and corneal stroma or were present intracellularly. ${ }^{5}$ We found in our rabbit model that $P s$. aeruginosa disappeared from the corneal surface within four hours from inoculation with $10^{6}$ bacteria, unless trauma was made with a $4 \mathrm{~mm}$ circular trephine into the anterior stroma. Invasion of the traumatised epithelial cells occurred after 7.5 minutes followed by bacteria present within the stroma at later intervals. ${ }^{6}$

Ps. aeruginosa has an outer membrane and cell wall composed of lipids, proteins and lipopolysaccharide from which project numerous pili (fimbriae) and a single polar flagellum. Pili have been studied for their adherence to epithelial cells of the human cornea $^{7}$ and mouth ${ }^{8,9}$ as well as mouse skin. ${ }^{10}$ Reichert ${ }^{7}$ studied the role of pili in an in vitro adherence assay system, using a homogenous purified pilin preparation, and demonstrated adherence to corneal epithelial cells which blocked subsequent adherence by isotopelabelled pilin. Paranchych et $\mathrm{al}^{9}$ found pseudomonas pili to be flexible filaments of 60 angstrom diameter and $2500 \mathrm{~nm}$ average length. They have sequenced the amino acids of the pilin protein and proposed a structural model. While adherence studies on buccal epithelial cells are convenient, they are open to error because only the outermost layer contains fibronectin, many are non-viable and have endogenous bacteria adherent to them. ${ }^{9}$ Paranchych et al, unlike Woods et $a l,{ }^{8}$ showed that buccal cell surface fibronectin did not affect the adherence of pseudomonas but both groups found adherence was inhibited by purified pili and anti-pilus antibody. This needs investigating on corneal epithelium.

Flagella have been shown in the mouse to have no role in adhesion of the bacterium to epidermal cells, when simultaneously the importance of pili for adherence was confirmed. ${ }^{10}$ However, less severe infections with non-flagellate (non-motile) mutants of Ps. aeruginosa have been demonstrated in experimental burn wounds in mice and rats possibly because of less resistance to phagocytosis. ${ }^{11}$ Vaccination of mice with flagella antigens protected them from lethal pseudomonas infection suggesting that antiflagella antibody enhances phagocytosis. ${ }^{11}$

\section{Extra-cellular factors:}

\section{Glycocalyx}

Ps. aeruginosa produces an extra-cellular glycocalyx called 'slime'. It is composed of glycolipoprotein, lipopolysaccharide (LPS) and a high molecular weight polysaccharide, which is derived from the LPS O side chain, and is immunogenic but non-toxic. ${ }^{12}$ This slime has been shown to impair the in vitro motility, endocytosis and phagosome formation of normal human polymorphonuclear neutrophils (PMNs), without altering their viability, and may contribute to the organism's virulence. ${ }^{13}$ Isolates from cystic fibrosis patients produce a mucoid extracellular substance of which the major component is mucoid exopolysaccharide similar in composition to seaweed alginate. ${ }^{13}$ While most isolates contain genetic information to produce it, phenotypic expression has not been reported from ocular isolates.

Studies of natural ecosystems have shown that a large percentage of bacteria adhere to inert surfaces and form microcolonies surrounded by a biofilm. ${ }^{14}$ Such biofilm-producing bacteria, including Ps. aeruginosa, have also been documented on mucosal surfaces, ${ }^{14}$ dead osteomyelitic bone ${ }^{15}$ and the surface of prostheses. ${ }^{16}$ Ps. aeruginosa occurs in the environment as a glycocalyx-enclosed microcolony or as a mobile or planktonic 'swarmer' cell but the former mode is numerically dominant providing protection from bacteriophages and phagocytosis ${ }^{17}$ the glycocalyx concerned is similar to 'slime'. Using electron microscopy Costerton et al demonstrated the use 


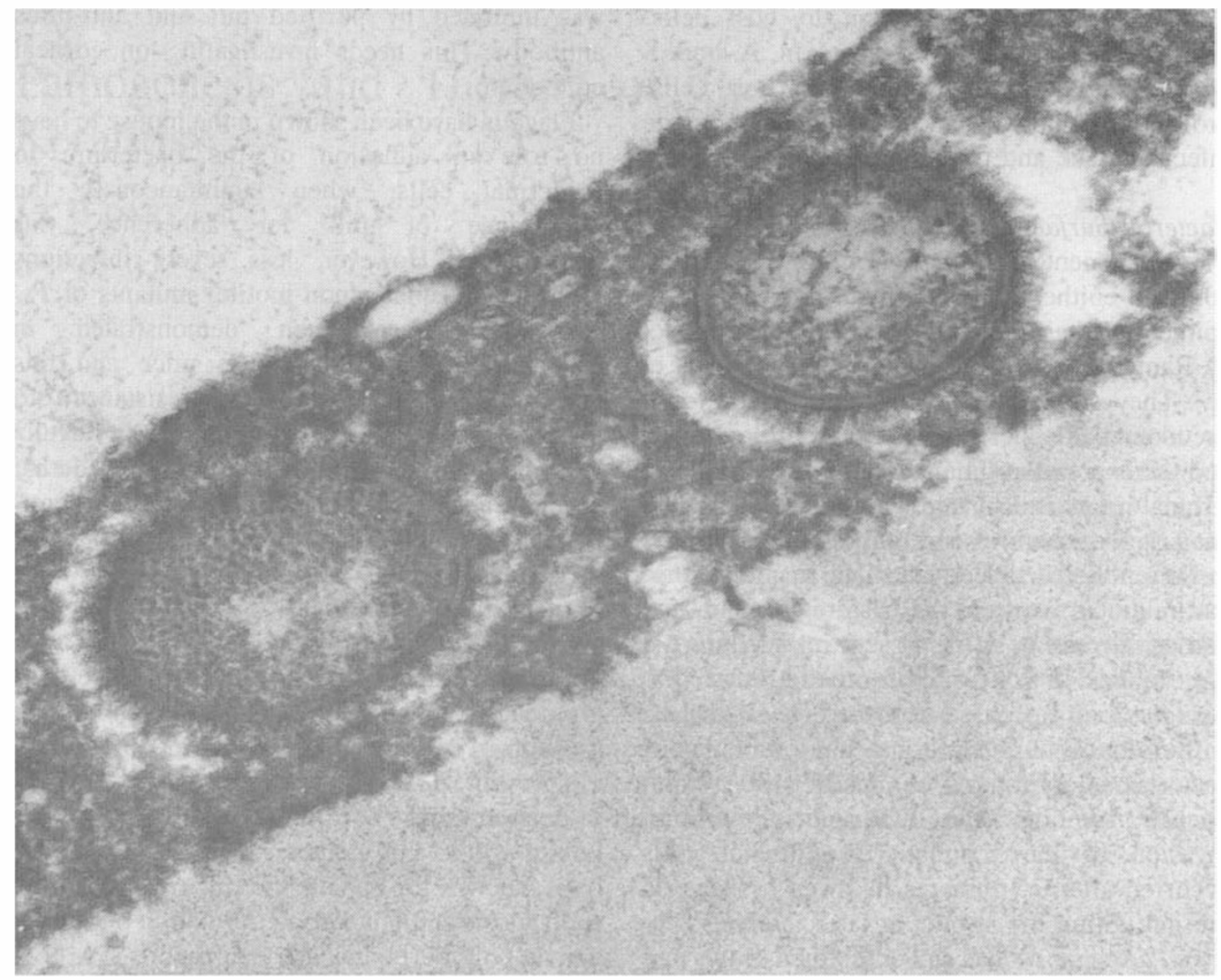

Fig 1. Transmission electron micrograph $(x 26,000)$ of colonised contact lens surface showing ruthenium red stained glycocalyx surrounding pseudomonads.

of ruthenium red staining for identifying the glycocalyx of Ps. aeruginosa within a microcolony. ${ }^{17}$ This glycocalyx can be stablised using antibodies to whole cells. Alternatively, ruthenium red stain can be incorporated during dehydration and fixation for electron microscopy at each stage of the process causing its precipitation. Slusher et $\mathrm{al}^{18}$ recently used this technique, with scanning and transmission electron microscopy, to demonstrate an in vitro polysaccharide-mediated biofilm adhesion between Ps. aeruginosa (and Staphylococcus epidermidis) and the surface of an extended wear contact lens. In our rabbit-wearing contact lens model exposed to $10^{6}$ cells of Ps. aeruginosa we have found that a similar ruthenium red-staining polysaccharide biofilm was present at three days in vivo on the outer surface of a colonised continuous wear hydrogel contact lens (Fig 1). ${ }^{19}$ This has implications for extended wear contact lenses and may be an important route for multiplication of pseudomonas prior to initiating keratitis if trauma occurs to corneal epithelium.

\section{Toxins and proteases}

Ps. aeruginosa produces exotoxins, proteolytic enzymes and haemolysins which can cause tissue necrosis. Many tissues are relatively resistant to pseudomonas toxins in the normal, immunocompetent host but this does not apply to the corneal stroma, possibly because of lack of a vascular network with associated rapid release of opsonic antibody and PMNs with the initial inflammatory response that occurs within minutes elsewhere. Similarly, in type I diabetics a reduced vasodilatory response, ${ }^{20}$ that has been measured for needle stick and thermal injury, has been postulated to predispose the host to early bacterial invasion.

Exotoxin $A$ This is the most lethal toxin pro- 
duced $\left(\mathrm{LD}_{50}=1 \mathrm{ug} / \mathrm{kg}\right.$ in mice $) .{ }^{21}$ Significant antitoxin immunoglobulin titres can be found in patients recovering from $P$ s. aeruginosa infection while survival of bacteraemic patients has been correlated with a high serum antitoxic titre at the onset of infection. ${ }^{21}$ Exotoxin $\mathrm{A}$ acts similarly to diphtheria toxin inhibiting mammalian protein synthesis by ADPribosylating elongation factor 2 . The kinetic parameters between the two toxins are similar but amino acid sequences are different.

It is excreted in an inactive form, a proenzyme of 66,000 daltons molecular weight, which is nonetheless highly toxic to animals and tissue culture cells. Synthesis and excretion depend on growth conditions and are inhibited by high levels of iron, as are other pseudomonas toxins. Exotoxin A is chromosomally encoded and is produced by over $90 \%$ of strains. ${ }^{22}$ The genetic locus of exotoxin A expression has been mapped and its regulation studied by cloning the gene that stimulates its expression. ${ }^{22}$

Exoenzyme $S$ This protein is another ADPribosyltransferase that is produced by $40 \%$ of isolates. ${ }^{21}$ It acts on mammalian cells but at a different site to elongation factor 2 . It is an important virulence determinant that has been investigated in a mutant strain deficient in its production, when the $\mathrm{LD}_{50}$ in the burned mouse model increased by $2 \times 10 .^{3}$

Proteolytic enzymes Two proteases have been isolated from culture fluids, called 'alkaline' and 'neutral' based on their optimum $\mathrm{pH}$ activity. ${ }^{21}$ Both proteases breakdown host protein and have been shown to interfere with phagocytosis by degrading immunoglobulins. Neutral protease, also called elastase, degrades elastin (not found in the cornea) as well as proteoglycans.

Using variants of Ps. aeruginosa Kawaharajo and $\mathrm{Homma}^{23}$ demonstrated correlation between production of proteases and severe corneal infection in mice. Ohman et $\mathrm{al}^{24}$ showed that exotoxin A was important for establishing corneal infection in mice but that elastase was not required, although his mutant did produce alkaline protease. Howe and Iglewski ${ }^{25}$ recently produced alkaline protease-deficient nonelastolytic mutants. In the mouse keratitis model they demonstrated loss of virulence by them with decreased visible corneal damage and recovery of fewer viable bacteria. Both proteases contribute to corneal destruction by degrading the corneal proteoglycans leading to the dispersal of collagen fibrils. ${ }^{26}$

Leukocidin This protein of 27,000 daltons is toxic for PMNs by acting on their membrane to cause influx of calcium which results in fusion of their nuclear segments. ${ }^{21}$ It is released in an inactive form that is activated by the proteases. Mutants lacking its production have not yet been produced for virulence testing.

Haemolytic toxins Two haemolysins are excreted of which one, which is heat labile, is a protein of 78,000 daltons with phospholipase C activity while the other is a glycolipid that acts by a detergent-like mechanism. ${ }^{21}$ Both are produced under phosphate-limiting growth conditions. These enzymes lyse red cells of various species, all of which have membranes containing phosphatidyl choline. Mutants have been produced which lack production of phospholipase $C$ (if cultured in the absence of phosphate) which has been mapped in the same region of the chromosome as the regulatory locus. ${ }^{21}$

Nicas and Iglewski recently compared isolates of Ps. aeruginosa from environmental (soil and water) sources and bacteraemic patients for levels of production of exotoxin A, proteases and phospholipase C activity. ${ }^{27}$ No significant differences were found demonstrating the pathogenic potential of the environmental strains.

\section{Host factors:}

Evidence from experimental pseudomonas keratitis has shown the importance of host factors in the elimination of bacteria ${ }^{28}$ particularly phagocytosis by PMNs. ${ }^{29}$ In the superficial injury model PMNs enter the wound within the first four-eight hours from the tear film followed by a substantial migration from the limbus at 48 hours ${ }^{28}$ when the tear film derived component may be of relatively little importance. ${ }^{30}$ Phagocytosis is mandatory to the elimination of $P$. aeruginosa. A recent study in immunocompetent and naive rats has demonstrated the importance to phagocytosis of an opsonic antibody response, probably IgG mediated, to $P$. aeruginosa together with complement components. The recruitment of PMNs was independent of this response ${ }^{29}$ for which active infection with $P$. aeruginosa, as well as bacterial products and endotoxin, are a very potent stimulus. ${ }^{30}$ 
The potential role of PMNs in corneal necrosis has been reviewed by Jones and there is no doubt that the products of PMN degranulation are capable of corneal necrosis. ${ }^{31}$ Phagocytosis is associated with degranulation of PMNs and degradation of the corneal stroma and overlying epithelium. ${ }^{28}$ This may be dependent on an antibody response and has been associated with increased PMN protease activity. ${ }^{29}$

We have already discussed evidence that suggests the importance of bacterial factors in corneal destruction. ${ }^{23-26}$ However the relative contributions of bacterial products and the results of PMN degradation to the progression of liquefactive necrosis is not certain. ${ }^{32}$ It is possible that the bacterial factors are more important for the establishment of infection following which PMN degradation may be more important in stromal necrosis. ${ }^{32}$ The relative role of pathogen and host response in the development of corneal necrosis may depend on the strain of $P$. aeruginosa. ${ }^{28}$

\section{Therapy of Pseudomonas Keratitis Aims}

The preceding review of the pathogenesis of pseudomonas keratitis has shown how this organism produces a formidable infection ${ }^{33}$ which, if unchecked, can rapidly progress to corneoscleritis, corneal perforation, and a resulting panophthalmitis. The aims of therapy are to prevent extension of the infection, eliminate the pathogen, control inflammation and encourage healing. Effective elimination of the organism is the key to treatment of early disease. However in late disease the remaining therapeutic objectives are of equal importance and consideration must be given to the toxicity of treatment, the control of the host response and, in patients with pre-existing ocular surface disease, the improvement of the corneal environment. The wide variety of clinical and experimental treatment alternatives and adjuncts to antibiotic therapy, that have been described, underlie the difficulty of achieving these aims. An understanding of the pathogenesis is vital both to the selection of current diagnostic and therapeutic measures as well as to future developments.

\section{Diagnosis}

Although $P$. aeruginosa is unusual amongst corneal pathogens in producing an almost pathognomonic keratitis ${ }^{34}$ early cases have no typical appearance and may present as corneal erosions $^{35}$ and small single or multiple foci of corneal suppuration. For these reasons, and because of the emergence of strains of $P$. aeruginosa resistant to gentamicin, ${ }^{36}$ successful therapy is dependent on isolating the organism and determining its antibiotic susceptibilities. The principles, pitfalls and methods of culturing corneal ulcers and of preparing smears for immediate microscopy have been exhaustively described..$^{34,37}$ We use a disposable hypodermic needle, rather than the commonly advocated Kimura spatula, to take multiple samples from the ulcer. Needles are easily available and allow samples of infected stroma to be more readily obtained from infected tissue and small lesions than the larger spatula.

\section{Initial treatment}

Our initial choice of antibiotic is made on the result of the Gram stain. ${ }^{38} \mathrm{~A}$ report of Gram negative rods is followed by treatment with half hourly topical fortified gentamicin $(15 \mathrm{mg} / \mathrm{ml})$. If there are mixed organisms or the report is negative or uncertain we start combined broad spectrum topical therapy with fortified gentamicin and cefuroxime given alternatively every quarter or half hour; the cefuroxime is omitted as soon as the diagnosis of $P$. aeruginosa is confirmed. Treatment is continued day and night, usually for 3 days when, providing there are signs of clinical improvement, the frequency is reduced to hourly during the day only. The rationale for this choice of antibiotic and route of administration is discussed below.

\section{Choice of antibiotic}

An aminoglycoside remains the first choice for treatment. Tobramycin has a $2-4 x$ lower mean inhibitory concentration (MIC) than gentamicin. ${ }^{39}$ However because of the very high levels of antibiotic that are achieved by topical therapy with fortified preparations, $20-80 x$ the MIC in a rabbit model, ${ }^{40}$ this is usually of little significance so that we have continued to use gentamicin in most cases. In addition to its bactericidal activity it has been shown that subinhibitory concentrations of gentamicin will inhibit the production of exotoxin A and elastase as well as inhibit bacterial adhesion to HEp-2 cells; ${ }^{41}$ this may account for some of the thera- 
peutic effect. The emergence of aminoglycoside resistant $P$. aeruginosa mutants during therapy is well recognised outside the eye, usually occurring after prolonged or topical therapy or in association with a foreign body. ${ }^{42-46}$ Such mutants have been linked with temperature sensitivity in the progenitor strains ${ }^{43}$ and have been shown to have reduced virulence properties ${ }^{44}$ although remaining capable of causing infection. ${ }^{45}$ These mutants may be showing persistence rather than resistance to aminoglycosides. ${ }^{46}$ Their possible occurrence in keratitis needs to be remembered particularly when infections recrudesce after prolonged treatment, a well documented event. ${ }^{33}$ Fortunately gentamicin resistant $P$. aeruginosa has been rare in our patients and the most frequent reason for changing to an alternative antibiotic has been the epithelial toxicity associated with topical aminoglycoside therapy which is discussed below. Alternatives to the aminoglycosides are the antipseudomonal penicillins and the extended spectrum cephalosporins. Icarcillin is less active than azlocillin but we have continued to use it because the topical preparation is stable in aqueous solution for up to 8 days (extrapolated from manufacturers information) whereas the stability of the newer penicillins is uncertain. Providing the isolate is sensitive it has been as effective and less toxic than fortified topical gentamicin. Of the extended spectrum cephalosporins ceftazidime has the most reliable antipseudomonal activity ${ }^{47}$ and is a useful reserve antibiotic. Of the newer antibiotics, the fluoroquinolones such as norfloxacin are stable in solution and are very active against $P$. aeruginosa. $^{39,48}$ They need to be evaluated in keratitis but resistance to them has emerged during single drug treatment of other $P$. aeruginosa infections.

Combined therapy of an antipseudomonal penicillin and aminoglycoside, on the grounds of synergism that occurs in vitro, is in widespread use. However the case for its use in keratitis is unsubstantiated and like others ${ }^{34}$ we consider that it adds an additional complication to topical treatment unless the infection is hospital acquired and likely to be resistant to gentamicin.

\section{Route and dose of administration}

It has been well established that intensive topical fortified aminoglycoside therapy in experimental keratitis will give high levels of drug in the cornea $^{40}$ and eliminate $P$. aeruginosa more effectively than the subconjunctival route in the rabbit model. ${ }^{28,49,50}$ Commercially available unfortified preparations have no place in treatment. Similarly, systemic therapy has been shown to be of no value in experimental keratitis. ${ }^{28,49,50}$ Although very high corneal peak levels of antibiotic are achieved by subconjunctival administration they later fall, within 3-6 hours, to well below those obtained by hourly topical fortified application. It is likely that subconjunctival antibiotic reaches the cornea by leak back from the conjunctival puncture site $^{29,49}$ as well as direct diffusion. ${ }^{29}$ Because of the short duration of the effect of subconjunctival injections, the associated pain and discomfort and the resulting conjunctival ischaemia and necrosis overlying the injection site this route, like systemic therapy, is rarely indicated. ${ }^{19,51}$ We use gentamicin fortified to $15 \mathrm{mg} / \mathrm{ml}$, rather than the commercial preparation at $3 \mathrm{mg} / \mathrm{ml}$, and the penicillins and cephalosporins in aqueous solution at $50 \mathrm{mg} / \mathrm{ml}$; the principles of manufacturing topical antibiotics have been described. ${ }^{38}$

\section{Modification of antibiotic treatment after culture results are available}

Treatment is changed to a single antibiotic as soon as culture results confirm the growth of $P$. aeruginosa and only modified, when sensitivities are available, if the organism is resistant to the antibiotic used. This is because the in vivo effect of antibiotics may be different from the in vitro effect due to modulation by bacterial host interaction, effect of host factors, such as phagocytosis and possibly the subinhibitory effects already described. However, if no apparent response occurs when the organism is not fully sensitive, combination with another antibiotic should commence.

\section{Adjunctive therapy}

Cycloplegia is the only adjunctive treatment indicated in the initial therapy of $P$. aeruginosa keratitis.

Steroid therapy has been widely discussed in relation to $P$. aeruginosa keratitis. Steroid suppresses PMN migration, reducing the numbers at an inflammatory site, their function, phagocytosis, intracellular digestion of phago- 
cytosed material and degranulation. ${ }^{52}$ In experimental studies steroids have not been shown to compromise effective antibiotic therapy. ${ }^{53,54}$ However combined antibiotic and steroid treatment of a resistant strain of $P$. aeruginosa in an experimental model enhanced bacterial growth, compared to antibiotic alone ${ }^{55}$ and delayed healing without improvement in the degree of corneal inflammation and scarring. ${ }^{56}$ Clinical experience has shown that steroid treatment may be associated with recurrent infection. ${ }^{33,57}$ There is little evidence that they have any part to play in the management of keratitis when the antibiotic susceptibility of the organism is unknown $\mathrm{n}^{56}$ and in the early stages of disease when replicating microorganisms are present. ${ }^{54}$ Despite their theoretical advantage in reducing the recruitment of PMNs, and consequent release of hydrolytic enzymes, there is reluctance to use them even late in $P$. aeruginosa keratitis because of known bacterial persistence. Also, for consideration, is their effect on decreasing fibroblastic activity and inhibition of healing which may in themselves precipitate corneal perforation. ${ }^{33.37 .38 .51}$

We have used steroids in only a few cases on a trial basis to control neovascularisation, which rarely starts before 10 days from onset, or in cases of late corneal melt when a trial can be indicated to test whether a reduction of PMN activity is beneficial.

Protease inhibitors such as cysteine, L-cysteine and calcium EDTA have not been found clinically useful ${ }^{37.38}$ and have been shown to have toxic effects on the corneal epithelium. ${ }^{58}$

\section{Complicated cases}

Deterioration of the patient who is on normally effective doses of antibiotic may be due to a number of factors which should be considered in turn. Organisms resistant to aminoglycosides are uncommon but occurred in $12 \%$ of one series $;^{36}$ routine sensitivity testing is an important guide to the management of this infection. Prolonged treatment is necessary to eliminate persistent organisms; exacerbations have followed a reduction in the frequency of topical treatment often when overnight medication is ceased. Ring infiltrates are common in microbial keratitis and can occur early in the disease, probably as a result of both classical and alternative pathway activation of complement. ${ }^{59}$ Providing there is optimal antibiotic therapy a trial of topical steroid treatment may reduce the inflammatory response in persistent ring infiltrates.

Prolonged times for closure of epithelial defects, following the apparent control of replicating bacteria, commonly occur in $P$. aeruginosa keratitis. If the clinical signs are improving but the ulcer is not epithelialising after 5 days to a week of adequate therapy consideration must be given to the toxicity of treatment, both of the antibiotic or its preservative. Aminoglycosides are amongst the most toxic of the antibiotics to the corneal epithelium ${ }^{60}$ and both benzalkonium and the mercurials (including thiomersal) have been shown to cause epithelial toxicity. ${ }^{58}$ For these reasons we use unpreserved medication where possible.

In patients with pre-existing ocular surface disease any corneal exposure should be corrected by lid taping or a temporary tarsorraphy. ${ }^{61}$ Therapeutic contact lenses have been recommended in this situation, ${ }^{33}$ but probably interfere more with corneal metabolism than tarsorraphy and may only be advantageous if protection is required from conjunctival keratinisation.

Persistent failure to epithelialise can also be accompanied by stromal degradation often from 1 to 2 weeks or later. If this persists despite the preceding measures a trial of steroid treatment should be considered. The use of conjunctival flaps for the management of this situation has been described. ${ }^{62}$ Because of possible persistence of $P$. aeruginosa for prolonged periods, the reduced corneal levels of antibiotic that are likely to result from the placing of a flap, and our experience of a recurrent infection under a flap, we cannot recommend this.

Perforation results from stromal necrosis and may occur early in untreated infection or late in unsuccessul therapy. If the perforation is less than $1-2 \mathrm{~mm}$ cyanoacrylate adhesive with or without a scleral patch should be attempted. ${ }^{63,64}$ If this fails, or for larger perforations, a therapeutic penetrating keratoplasty is needed after intensive topical, and in this case systemic, therapy for three days to eradicate pseudomonads from the cornea as far as possible. Providing all the affected tissue is excised, which may require a corneoscleral graft, this can produce a dramatic improvement but at the cost of a rejection rate of nearly $50 \%$ in the first six 
months. ${ }^{65,66}$ Unlike some others, because of both the risk of recurrent infection and of rejection we do not advocate either lamellar ${ }^{66}$ or penetrating keratoplasty ${ }^{65}$ before perforation.

\section{Experimental therapy}

Many other treatment modalities have been proposed for evaluation in experimental models from laser phototherapy, ${ }^{67}$ topical immunotherapy, ${ }^{68}$ antibiotic iontophoresis, ${ }^{69}$ inhibition of elastase ${ }^{26,70}$ and cryotherapy. ${ }^{\pi}$ Of these only cryotherapy has been reported in clinical use and may have a role to play in the treatment of $P$. aeruginosa scleritis. Iontophoresis deserves further evaluation. The inhibition of bacterial proteases during therapy is of doubtful relevance as effective antibiotic treatment will rapidly reduce the numbers of bacteria elaborating the enzymes. However, immunisation of compromised patients to give high antibody titres to pilin antigen to reduce adherence, to somatic and flagella antigens to enhance opsonisation, or to the proteases to prevent early corneal destruction may be evaluated in the future as prophylaxis.

We are grateful for the assistance of Dr I Grierson, Mr R Howes and Mr J Peacock and to Mrs S Lawrence for library facilities.

\section{References}

${ }^{1}$ Kreger AS. Pathogenesis of Pseudomonas aeruginosa Ocular Diseases. Rev Inf Dis 1983; 5 (supplement 5): S931-5.

${ }^{2}$ Berk RS, Hazlett LD, Beisel KW. Genetic studies on resistant and susceptibility genes controlling the mouse cornea to infection with Ps. aeruginosa. Antibiot Chemother 1987; 39: 83-91.

${ }^{3}$ Pollack M. The Virulence of Pseudomonas aeruginosa. Rev Inf Dis 1984; 6 (supplement 3): S617-26.

${ }^{4}$ Ramphal R, McNiece MT, Polack FM. Adherence of $P$ s. aeruginosa to the injured cornea: a step in the pathogenesis of corneal infections. Ann Ophthalmol 1981; 13: 421-5.

${ }^{5}$ Stern GA, Lubniewski A, Allen C. The interaction between Ps. aeruginosa and the corneal epithelium. Arch Ophthalmol 1985; 103: 1221-5.

${ }^{6}$ Dart JK, Peacock JL, Hughes R, et al. Bacterial colonisation of rabbit corneal epithelium. Invest Ophthalmol Vis Sci 1987; 28 (3): 174 (abstr).

${ }^{7}$ Reichert RW, Das NE, Zam ZS. Adherence properties of Pseudomonas pili to epithelial cells of the human cornea. Curr Eye Res 1983; 2: 289-93.
${ }^{8}$ Woods DE, Straus DC, Johanson WG, et al. Factors influencing the adherence of $P$ s. aeruginosa to mammalian buccal epithelial cells. Rev Inf Dis 1983; 5 (supplement 5): S846-51.

${ }^{9}$ Paranchych W, Sastry PA, Volpel K, et al. Fimbrae (pili): molecular basis of Ps. aeruginosa adherence. Clin Invest Med 1986; 9: 113-8.

${ }^{10}$ Sato H, Okinaga K. Role of pili in the adherence of $P$ s. aeruginosa to mouse epidermal cells. Inf Immunol 1987; 55: 1774-8.

${ }^{11}$ Holder IA, Naglich JG. Experimental studies of the pathogenesis of infections due to Ps. aeruginosa: immunization using divalent flagella preparations. J Traum 1986; 26: 118-22.

12 Pier GB. Pseudomonas aeruginosa surface polysaccharide vaccines. Antibiot Chemother 1985; 36: 157-67.

${ }^{13}$ Laharrague PF, Corberand JX, Fillola G, et al. In vitro effect of the slime of Ps. aeruginosa on the function of human polymorphonuclear neutrophils. Inf Immunol 1984; 44: 760-2.

${ }^{14}$ Gristina AG, Costerton JW. Bacterial adherence and the glycocalyx and their role in musculoskeletal infection. Ortho Clin $N$ Am 1984; 15: 517-35.

${ }^{15}$ Gristina AG, Oga M, Webb LX, et al. Adherent bacterial colonization in the pathogenesis of osteomyelitis. Science 1985; 228: 990-3.

${ }^{16}$ Gristina AG, Costerton JW. Bacterial adherence to biomaterials and tissue. J Bone Joint Surg 1985; 67: 264-73.

${ }^{17}$ Costerton JW, Lam J, Lam K, et al. The role of the microcolony mode of growth in the pathogenesis of $P$ s. aeruginosa infections. Rev Inf Dis 1983; 5 (suppl 5): S867-73.

${ }^{18}$ Slusher MM, Myrvik QN, Lewis JC, et al. Extended-wear lenses, biofilm and bacterial adhesion. Arch Ophthalmol 1987; 105: 110-15.

${ }^{19}$ Dart JKG, Grierson I, Peacock J, et al. Ocular surface, contact lens and bacterial interactions: histochemistry of the colonised contact lens surface. Invest Ophthalmol Vis Sci 1988; 29: 231 (abstr).

${ }^{20}$ Rayman S, Williams SA, Spencer PD, et al. Impaired microvasculature hyperaemic response to minor skin trauma in type I diabetes. $\mathrm{Br} \mathrm{Med}$ $J$ 1986; 292: 1295-8.

${ }^{21}$ Lory S, Tai PC. Biochemical and genetic aspects of Ps. aeruginosa virulence. Curr Top Microbiol Immunol 1985; 118: 53-69.

${ }^{22}$ Hedstrom RC, Funk CR, Kaper JB, et al. Cloning of a gene involved in regulation of exotoxin A expression in Ps. aeruginosa. Inf Immunol 1986; 51: 37-42.

${ }^{23}$ Kawaharajo K, Homma JY. Pathogenesis of the mouse keratitis produced with Ps. aeruginosa. Jap J Exp Med 1975; 45: 515-24. 
${ }^{24}$ Ohman DE, Burns P, Iglewski BH. Corneal infections in mice with toxin $\mathrm{A}$ and elastase mutants of Ps. aeruginosa. J Inf Dis 1980; 142: 547-55.

${ }^{25}$ Howe TR, Iglewski BH. Alkaline protease deficient mutants of Ps. aeruginosa; isolation and characterization in vitro and in a mouse eye model. Inf Immunol 1984; 43: 1058-63.

${ }^{26}$ Kessler E, Blumberg S. Specific inhibitors of Ps. aeruginosa elastase as potential drugs for the treatment of Pseudomonas keratitis. Antibiot Chemother 1987; 39: 102-112.

${ }^{27}$ Nicas IT, Iglewski BH. Production of elastase and other exoproducts by environmental isolates of Ps. aeruginosa. J Clin Microbiol 1986; 23: 967-9.

${ }^{28}$ Hyndiuk RA. Experimental pseudomonas keratitis. Trans Am Ophthalmol Soc 1981; LXXIX: 541-624.

${ }^{29}$ Twining SS, Lohr KM, Moulder JE. The immune system in experimental pseudomonas keratitis: model and early effects. Invest Ophthalmol Vis Sci 1986; 27: 507-15.

${ }^{30}$ Chusid MJ, Davis SD. Polymorphonuclear leukocyte kinetics in experimentally induced keratitis. Arch Ophthalmol 1985; 103: 270-4.

${ }^{31}$ Jones DB. Pathogenesis of bacterial and fungal keratitis. Trans Ophthalmol Soc UK 1978; 98: 367-71.

${ }^{32}$ Steuhl K-P, Doring G, Henni A, et al. Relevance of host-derived and bacterial factors in Pseudomonas aeruginosa corneal infections. Invest Ophthalmol Vis Sci 1987; 28: 1559-68.

${ }^{33}$ Laibson PR. Cornea and sclera. Arch Ophthalmol 1972; 88: 553-74.

${ }^{34}$ Jones DB. Strategy for the initial management of suspected microbial keratitis. In: Symposium on medical and surgical diseases of the cornea. St Louis; CV Mosby, 1980: 86-119.

${ }^{35}$ Clemons CS, Cohen EJ, Arentsen JJ, et al. Pseudomonas ulcers following patching of corneal abrasions associated with contact lens wear. CLAO J 1987; 13: 161-4.

${ }^{36}$ Roussel TJ, Osato MS, Robinson NM, et al. Resistant pseudomonas keratitis. J Ocul Ther Surg 1984; 3: 136-8.

${ }^{37}$ Jones DB. Decision-making in the management of microbial keratitis. Ophthalmology 1981; 88: 814-20.

${ }^{38}$ Baum JL, Jones DB. Initial therapy of suspected microbial corneal ulcers. Surv Ophthalmol 1979; 24: 97-116.

${ }^{39}$ Goldstein EJG, Citron DM, Bendon L, et al. Potential of topical norfloxacin therapy: comparative in vitro activity against clinical ocular bacterial isolates. Arch Ophthalmol 1987; 105: 991-4.
${ }^{40}$ Baum J. Treatment of bacterial ulcers of the cornea in the rabbit: a comparison of administration by eye drops and subconjunctival injections. Trans Am Ophthalmol Soc 1982; LXXX: 369-90.

${ }^{41}$ Ogaard AR, Bjoro K, Bukholm G, et al. Pseudomonas aeruginosa virulence factors: modifications by sub-inhibitory concentrations of carbenicillin or gentamicin. Acta Path Microbiol Immunol Scand Sect B 1986; 94: 63-8.

${ }^{42}$ Seal DV, Strangeways JEM. Resistant pseudomonads in a neurosurgical unit. Lancet 1975; i: 48.

${ }^{43}$ Seal DV, Strangeways JEM. Temperature sensitivity and gentamicin resistance in Pseudomonas aeruginosa. Lancet 1975; ii: 501.

${ }^{44}$ Clark RB, Janda JM, Bottone EJ. Phenotypic factors correlated with the absence of virulence among gentamicin resistant Pseudomonas aeruginosa strains. J Clin Microbiol 1984; 20 : 235-8.

${ }^{45}$ Bayer AS, Norman DC, Kim KS. Characterisation of impermeability variants of Pseudomonas aeruginosa isolated during unsuccessful therapy of experimental endocarditis. Antimicrob Agents Chemother 1987; 31: 70-75.

${ }^{46}$ Bryan LE, Godfrey AJ, Schoffardt T. Virulence of Pseudomonas aeruginosa strains with mechanisms of microbial persistence for $\beta$ lactam and aminoglycoside antibiotics in a mouse infection model. Can J Microbiol 1985; 31: 377-80.

${ }^{47}$ Wise R. Antimicrobial agents: a widening choice. Lancet 1987; i: 1251-4.

${ }^{48}$ Finch R. Anti-infectives. $\mathrm{Br}$ Med $J$ 1988; 296: 261-4.

${ }^{49}$ David SD, Sarff LD, Hyndiuk RA. Comparison of therapeutic routes in experimental pseudomonas keratitis. Am J Ophthalmol 1979; 87: 710-6.

${ }^{50}$ Leibowitz HM, Ryan WJ, Kupferman A. Route of antibiotic administration in bacterial keratitis. Arch Ophthalmol 1981; 99: 1420-3.

${ }^{51}$ Wilson LA. Acute bacterial infection of the eye; bacterial keratitis and endophthalmitis. Trans Ophthalmol Soc UK 1986; 105: 43-60.

${ }^{52}$ Spence DJ, Schanzlin DJ. Corticosteroid therapy in infectious external ocular diseases. In Smolin G, Okumoto $M$ (eds): Antimicrobial agents in ophthalmology. New York; Masson Pub Inc 1983: 87-94.

${ }^{53}$ Leibowitz HM, Kupferman A. Topically administered corticosteroids: effect on antibiotictreated bacterial keratitis. Arch Ophthalmol 1980; 98: $1287-90$.

${ }^{54}$ Coster DJ, Badenoch PR. Host, microbial, and pharmacological factors affecting the outcome of suppurative keratitis. Br J Ophthalmol 1987; 71: 96-101. 
${ }^{55}$ Stern GA, Okumoto M, Friedlander M, et al. The effect of combined gentamicin-corticosteroid treatment on gentamicin-resistant pseudomonas keratitis. Ann Ophthalmol 1980; 12: 1011-4.

${ }^{56}$ Smolin G, Okumoto M, Leong-Sit L. Combined gentamicin-tobramicin-corticosteroid treatment II. Effect on gentamicin-resistant pseudomonas keratitis. Arch Ophthalmol 1980; 98: 473-4.

${ }^{57}$ Alfonso E, Kenyon KR, Ormerod D, et al. Pseudomonas corneoscleritis. Am J Ophthalmol 1987; 103: 90-8.

${ }^{58}$ Burstein NL. Corneal cytotoxicity of topically applied drugs, vehicles, and preservatives. Surv Ophthalmol 1980; 25: 15-30.

${ }^{59}$ Mondino BJ, Brown SI, Rabin BS. Role of complement in corneal inflammation. Trans Ophthalmol Soc UK 1978; 98: 363-6.

${ }^{60}$ Petrousos G, Guimaraes R, Giraud J, et al. Antibiotics and corneal epithelial wound healing. Arch Ophthalmol 1983; 101: 1775-8.

${ }^{61}$ Kirkness CM, Adams GGW, Dilly PN, et al. Botulinum toxin A-induced protective ptosis in corneal disease. Ophthalmology 1988; 95: 473-80.

${ }^{62}$ Buxton JM, Fox ML. Conjunctival flaps in the treatment of refractory pseudomonas corneal abscess. Ann Ophthalmol 1986; 18: 315-8.

${ }^{63}$ Mandlebaum S, Udell IJ. Tissue adhesives. In Abbott RL (ed): Surgical intervention in corneal and external diseases. Orlando Florida (USA); Grune and Stratton Inc 1987: 89-93.

${ }^{64}$ Hyndiuk RA, Hull DS, Kinyoun JL. Free tissue patch and cyanoacrylate in corneal perforations. Ophthalmic Surg 1974; 5: 50-5.

${ }^{65}$ Thiel H-J, Steuhl K-P, Doring G. Therapy of Pseudomonas aeruginosa eye infections. Antibiot Chemother 1987; 39: 92-101.

${ }^{66}$ Malik SRK, Singh G. Therapeutic keratoplasty in Pseudomonas pyocyaneus corneal ulcers. $\mathrm{Br} \mathrm{J}$ Ophthalmol 1971; 55: 326-30.

${ }^{67}$ Fromer C, L'Esperance F. Argon laser phototherapy of pseudomonas corneal ulcers. Invest Ophthalmol Vis Sci 1971; 10: 1-8.

${ }^{68}$ Welsh NH, Rauch AJ, Gaffin SL. Topical immunotherapy for pseudomonas keratitis in rabbits; use of antilipopolysaccharide plasma. $\mathrm{Br}$ J Ophthalmol 1984; 68: 828-32.

${ }^{69}$ Rootman DS, Hobden JA, Jantzen JA, et al. Iontophoresis of tobramycin for the treatment of experimental pseudomonas keratitis in the rabbit. Arch Ophthalmol 1988; 106: 262-5.

${ }^{70}$ Kessler E, Spierer A, Blumberg S. Specific inhibition of Pseudomonas aeruginosa elastase injected intracorneally in rabbit eyes. Invest Ophthalmol Vis Sci 1983; 24: 1093-7.

${ }^{71}$ Eiferman RA. Cryotherapy of pseudomonas keratitis and scleritis. Arch Ophthalmol 1979; 97: 1637-9. 